\title{
The characterization of the most-liked reduced-fat Havarti-type cheeses
}

\author{
T. Ritvanen, ${ }^{* 1}$ L. Lilleberg, ${ }^{*}$ T. Tupasela,† U. Suhonen, $\ddagger$ S. Eerola, ${ }^{*} \S \mathrm{T}$. Putkonen, ${ }^{*}$ and K. Peltonen \\ ${ }^{*}$ Finnish Food Safety Authority Evira, Department of Chemistry and Toxicology, FIN-00790 Helsinki, Finland \\ †MTT Agrifood Research Finland, Biotechnology and Food Research, FIN-31600 Jokioinen, Finland \\ $\ddagger$ Valio Ltd., FIN-00039 Valio, Finland \\ $\S R O A L$ Ltd., FIN-05200 Rajamäki, Finland
}

\section{ABSTRACT}

In Finland, official recommendations state that reduced-fat cheese should be used in the everyday diet. Finnish consumers are increasingly willing to consume food with a reduced fat content, and sales of reducedfat cheeses have been increasing. The consumers who participated in this study ( $\mathrm{n}=153 ; 17$ to $78 \mathrm{yr}$ old $)$ ate reduced-fat cheeses on a weekly basis. They were recruited from supermarket customers living in a metropolitan area in Finland. The object of this study was to determine which kind of reduced-fat Havarti-type cheeses were most liked. The study consisted of a consumer test, sensory descriptive analysis, and chemical analysis of commercial reduced-fat Havarti-type cheeses $(n=10)$. The results of the sensory quantitative descriptive analysis were compared with consumer hedonic ratings by external preference mapping. In addition, information on composition (fat, salt, and free amino acids) was gathered and compared with the hedonic ratings. The preferred sensory properties were a pale appearance, sticky texture, and rich flavor. However, the consumers could be grouped according to their preferences on appearance and consistency. The main attributes contributing to the grouping of consumers were stickiness, hardness, and yellow color. The least preferred cheeses among all Finnish consumers were those with the lowest flavor intensities. The consumers preferred the cheeses with the highest salt content.

Key words: preference mapping, quantitative descriptive analysis, reduced-fat cheese

\section{INTRODUCTION}

Consumers' willingness to purchase food with a reduced fat content has been increasing in Finland during recent years. In 2004, almost half of all cheese consumed in Finland was reduced-fat cheese. A meta-analysis by Astrup et al. (2000) advocated a low-fat diet as a way

Received March 30, 2010.

Accepted August 2, 2010.

${ }^{1}$ Corresponding author: tiina.ritvanen@evira.fi to control BW. Furthermore, a recent review (ScholzAhrens and Schrezenmeir, 2006) claimed that reducedfat dairy products positively affect metabolic health as they can help with weight reduction. In addition to their reduced energy content, the calcium content of dairy products may prevent metabolic syndrome. However, other diets might be as beneficial to metabolic health as a low-fat diet. Some studies have indicated that a low-carbohydrate diet could be as good as or better than a low-fat diet in decreasing the risk of the metabolic syndrome (Meckling et al., 2004). Nonetheless, it is an official recommendation that reduced-fat cheese should be used in everyday life. The American Dietetic Association and the Dietitians of Canada also recommend low-fat dairy products (Kris-Etherton et al., 2007).

Reduced-fat cheeses have been characterized as bitter (e.g., Madsen and Ardö, 2001; Mistry, 2001), chewy (Gwartney et al., 2002), firm (Fenelon and Guinee, 2000), or considered to be of "low quality" (Jack et al., 1994). With time, however, many technological advances have been introduced to improve the sensory quality of low-fat cheeses (Mistry, 2001; Banks, 2004).

Havarti-type cheeses are the most popular cheese varieties in Finland, along with Edam and Emmental cheeses (AC Nielsen ScanTrack, 2001; www.nielsen. com). The typical fat content of Havarti-type cheeses is 45 to $55 \%$ of DM, with a minimum DM content of $50 \%$ (by weight) (Codex Standard for Havarti, 267-1966). Havarti-type cheeses are interior-ripened cheeses with a mild, creamy flavor and a fresh acidic taste. This semihard cheese resembles Tilsit and was made in earlier times on a farm in Havarti, in North Zealand, Denmark. It is normally made from cow milk but there are no limitations on the breed of cow. In northern Europe, the milk is typically pasteurized. Originally, the whey was drained off before cheese pressing. Today, manufacturing processes can vary to some extent. Rennet is used and the curd is pressed and drained in molds. The Havarti-type cheese is a cooked cheese in which the fat content, size, and shape may vary. The cheese may be wrapped in a film or allowed to form a rind, which may be rather dry with a tendency to greasiness. The color 
of the rind is typically yellow-red to brown and the body is light yellow with numerous small, irregularly shaped holes. Havarti-type cheese is softer than other semihard varieties and has a fuller flavor. The cheeses are matured for 4 wk to 6 mo. (Davis, 1976).

In addition to fat, salt and free amino acids (FAA) are known to affect cheese flavor significantly. The FAA are produced during maturing due to proteolysis. Some FAA are known to be bitter-tasting compounds. The salt content in reduced-fat cheeses might be increased to enhance flavor (Saint-Eve et al., 2009) and decrease bitterness in cheeses (Mistry and Kasperson, 1998). Furthermore, salt content is an important factor in texture. However, salt is a well-known contributor to hypertension (Karppanen and Mervaala, 2006). The limit for heavy salting in cheeses is $1.3 \%$ by weight (Decision of the Ministry of Trade and Industry on Labeling of Foodstuffs 2.12.2004/1084; Anon., 2007) in Finland. As cheese consumption has increased, the significance of salt intake from cheeses has increased accordingly.

Cheeses with at least a $30 \%$ reduction in fat content are called reduced-fat cheeses (Regulation EC No. 1924/2006 on nutrition and health claims made on foods). In a previous study (Ritvanen et al., 2005), we found that the common reduced-fat cheeses on the Finnish market are considered by consumers to be just as pleasant as regular fat cheeses. Levis et al. (2000) also have demonstrated that reduced-fat cream cheeses with $40 \%$ less fat can be preferred as much as their fullfat counterparts. However, some differences between attributes concerning pleasantness of regular-fat and reduced-fat Havarti-type cheeses were reported. "Aftertaste" and "flavor intensity" were more important to the pleasantness of reduced-fat cheeses than that of regular-fat cheeses, which might indicate different reasons behind a preference for a particular reduced-fat Havarti-type cheese. In addition, the variation in mean hedonic scores for reduced-fat cheeses was greater than for regular-fat Havarti-type cheeses.

The objective of this study was to discover which types of reduced-fat Havarti-type cheeses are most liked when the comparison is limited exclusively to reducedfat cheeses. In contrast to Childs and Drake (2009), we assumed that regular consumers of reduced-fat cheeses do not expect the cheese to resemble a full-fat cheese. It has been demonstrated that eating cheeses with a modified fat content may affect preference (Levis et al., 2000). For the study, reduced-fat cheeses were considered a distinct dairy product. Thus, by limiting the samples to reduced-fat cheeses, it was possible to highlight the differences among these cheeses, rather than focusing on the differences between reduced-fat cheeses and their full-fat counterparts. In addition, the negative attitude toward low-fat dairy products could be
Table 1. The dairies producing the commercial cheeses examined in this study

\begin{tabular}{llc}
\hline Dairy & Location & Samples, n \\
\hline Arla Foods co-operative dairy & Viby, Denmark & 1 \\
Ilmajoki co-operative dairy & Ilmajoki, Finland & 1 \\
Ingman Ltd. & Söderkulla, Finland & 1 \\
Juustoportti Ltd. & Jalasjärvi, Finland & 1 \\
Milka co-operative dairy & Kaitsor, Finland & 2 \\
NorrOst dairy & Malmö, Sweden & 1 \\
Skåne mejerier dairy & Malmö, Sweden & 1 \\
Valio Ltd. & Helsinki, Finland & 2 \\
\hline
\end{tabular}

negated because full-fat cheeses were excluded from the comparison (Kähkönen and Tuorila, 1999; Yackinous et al., 1999). The results of the sensory quantitative descriptive analysis (QDA; Stone and Sidel, 1993) were compared with hedonic ratings by external preference mapping. Preference mapping is a group of techniques applied to relate sensory attributes and consumer liking and to characterize market segmentation (McEwan, 1996; Helgesen et al., 1997). It has been widely used for full-fat cheeses (Young et al., 2004; Hersleth et al., 2005; Caspia et al., 2006). In addition, the fat, salt, and FAA contents the cheeses were correlated with the hedonic ratings and QDA.

\section{MATERIALS AND METHODS}

\section{Samples}

The samples were 10 commercial Havarti-type cheeses with reduced fat contents. The cheeses with the highest market volumes were chosen. The samples were produced in 8 dairies (Table 1). The subsamples for different analyses were always from the same batch. The total amount of a cheese was approximately $16 \mathrm{~kg}$.

\section{Sensory Profile}

The sensory profile test was carried out by the QDA (Stone and Sidel, 1993). The assessors $(\mathrm{n}=9)$ were experts who have been involved in the sensory analysis of cheeses for more than 5 years. Three separate training sessions (lasting $4 \mathrm{~h}$ each) with various cheeses and reference samples were organized. In addition, reference materials were available for the assessors for independent training between training sessions. The jury in a previous study (Ritvanen et al., 2005) used this same profiling method; thus, a revision of the method was considered adequate. The sufficiency of training was evaluated by examining deviations of the jury from the mean values.

The sensory attributes concerned appearance, texture, and flavor (Table 2). A linear scale $(10 \mathrm{~cm}$, ver- 
Table 2. The sensory attributes in the quantitative descriptive analysis

\begin{tabular}{lll}
\hline Attribute & Abbreviation & Definition \\
\hline Yellowness & Yell & Intensity of color of cheese mass \\
Evenness of color & ColEven & Evenness of color in cutting surface; evenness means not speckled, mottled, streaky, or marbled \\
Deviation of holes & HDev & Evenness of hole deviation on the surface \\
Amount of holes & HAm & Average number of holes in the cutting surface \\
Size of holes & HSi & Size of holes \\
Hardness & Hard & Softness/hardness of cheese mass as determined by fingers \\
Elasticity & Elas & Drag felt while bending a piece of cheese; elastic cheese is difficult to break \\
Toughness & Tough & Difficulty of chewing as determined when a piece is ready to be swallowed \\
Crystallinity & Cryst & A characteristic of aged cheese; crystals grate in the mouth \\
Stickiness & Sticky & Sticky cheese sticks to teeth and mouth surfaces \\
Flavor intensity & FlavInt & Intensity of all flavors as sensed when tasting the cheese for the first time \\
Saltiness & Salty & Salty taste sensation elicited by salts \\
Sourness & Sour & Sour taste sensation elicited by acids \\
Rich flavor & Flav_rich & Greasy mouthfeel in balance with flavor \\
Balance of flavors & Flav_bal & Balance of flavor means that no one flavor overwhelms the other flavors \\
Bitterness & Bitter & Bitter taste sensation as elicited by caffeine or free AA \\
Aftertaste & AfterT & Intensity of taste determined 30 s to 1 min after swallowing (or spitting) \\
\hline
\end{tabular}

bally anchored at both ends; e.g., weak, strong) was used. One attribute (size of the holes) was additionally anchored in the middle. All 10 cheeses were presented to assessors in 1 session, and no time limit for evaluation was set. The samples were coded with 3 -digit numbers and presented to the assessors in a randomized order. The attributes concerning appearance were evaluated by test samples with the same size as in the consumer packages (approximately $5 \mathrm{~cm} \times 7 \mathrm{~cm} \times 12 \mathrm{~cm}$ ), and the attributes concerning flavor were evaluated by test samples sized approximately $4 \mathrm{~cm} \times 5 \mathrm{~cm} \times 2 \mathrm{~cm}$. The texture was evaluated by both test sample sizes. Sample temperature was $14 \pm 2^{\circ} \mathrm{C}$. The sensory profile test was carried out in duplicate.

\section{Consumer Test}

A product test for liking was arranged. Consumer preference for appearance, mouth feel, flavor, and overall liking were evaluated with the 9-point classical hedonic scale (Peryam and Pilgrim, 1957). Points 6 to 9 meant that the subject liked the sample, points 1 to 4 represented disliking the sample, and point 5 was taken as neither liking nor disliking the sample.

The attitude of the consumer toward low-fat food can influence preference (Solheim and Lawless, 1996), so only regular consumers of reduced-fat cheeses were surveyed. Attitude was evaluated indirectly. When an individual reported regular consumption of reduced-fat cheeses, he or she was estimated to have at least a neutral attitude. Likewise, Levis et al. (2000) suggested that in the case of individuals currently consuming higher fat products, expectations about modified-fat products may be different.

Consumers $(\mathrm{n}=153)$ were clients in 3 supermarkets in a metropolitan area of Finland. The consumers were recruited personally. They were told that samples were of reduced-fat Havarti-type cheeses. The consumers were mostly women (68\%) 17 to 78 (mean 49) yr old, and $57 \%$ of the consumers had a secondary education. Consumers tested were regular eaters of reduced-fat cheeses; $86 \%$ reported eating these products at least weekly.

The samples (approximately $4 \mathrm{~cm} \times 5 \mathrm{~cm} \times 2 \mathrm{~cm}$ ) were coded with letters randomly extracted from the middle parts of the alphabet and presented in a randomized order. Paper ballots were used. Consumers were requested to rinse their mouths with water between samples.

\section{Chemical Analysis}

A test sample of approximately $500 \mathrm{~g}$ was homogenized for chemical analyses. Dry matter, fat, and salt were analyzed in duplicate by International Dairy Federation standard methods (IDF, 1982; IDF, 1986; IDF, 1988; respectively). The above methods are accredited in our laboratory according to EN ISO/IEC 17025. The FAA were analyzed by a titration method (Moisio and Heikonen, 1996).

\section{Statistics}

The results of the QDA were analyzed by 2-way ANOVA (factor: cheese, assessor) and principal components analysis. The results of the consumer hedonic tests were assessed by ANOVA (factor: cheese), and statistically significant differences $(P<0.05)$ were tested by Tukey's test. The experimental design in the consumer hedonic tests was a randomized block (block $=$ consumer $)$. Correlations $(P<0.05)$ of the consumer hedonic tests, the chemical analysis, and the QDA results were obtained by Spearman rank correlation test. 
Preference mapping was done by principal component regression. The results of the QDA were $\mathrm{x}$-variables, and the hedonic ratings (overall liking) were y-variables. Hierarchical cluster analysis (complete linkage) was carried out to divide the consumers into subgroups according to their preference similarities. The statistical tests were carried out using Statistix for Windows (2.0, Analytical Software, Tallahassee, FL), Unscrambler (9.2, CAMO ASA, Oslo, Norway), and SPSS for Windows (11.5, SPSS Inc., Chicago, IL).

\section{RESULTS AND DISCUSSION}

\section{Sensory Profile}

The differences between cheeses in all attributes except crystallinity, toughness, and bitterness were statistically significant $(P<0.05)$. The results of the QDA are presented in Table 3 .

Bitterness has been linked with reduced-fat cheeses (Mistry, 2001), but in this study, reduced-fat Havartitype cheeses were rated as having only a moderate bitter taste (bitterness ranged from 3.7 to 5.8). In our earlier study (Ritvanen et al., 2005), similar values for bitterness were observed for all Havarti-type cheeses. Likewise, in Danbo cheeses with different fat contents (Madsen and Ardö, 2001), the level of bitterness was low and no significant differences were found among the cheeses. Other characteristics associated with reduced-fat cheeses in general are that they are chewy ("tough") and firm ("hard"). The tested cheeses were slightly tough (toughness ranged from 3.1 to 4.8 ). This is in accordance with an earlier study (Ritvanen et al., 2005), where reduced-fat Havarti-type cheeses were as chewy as their regular-fat counterparts. Nevertheless, the cheeses varied significantly in hardness (1.4 to 7.0; $P<0.001)$. Elasticity ranged from 2.6 to $6.4(P<$ $0.001)$.

A full, creamy flavor is characteristic for Havarti-type cheese. "Rich flavor" and "balance of flavors" ranged from 4.0 to 6.2 and from 3.6 to 6.4 , respectively $(P<$ 0.001 for both attributes). In addition, all cheeses had a moderate sour (4.9 to $6.6 ; P<0.01$ ) and salty taste (3.0 to $6.5 ; P<0.001)$. It can be concluded that the cheeses were sufficiently different from each other to allow us to determine the characteristics preferred by consumers.

\section{Consumer Test}

All cheeses performed well in the consumer test for liking. A summary of the results is presented in Table $4(\mathrm{df}=9,1,368$; pleasantness of appearance: $F$ $=10.615, P<0.000$; pleasantness of mouth feel: $F=$

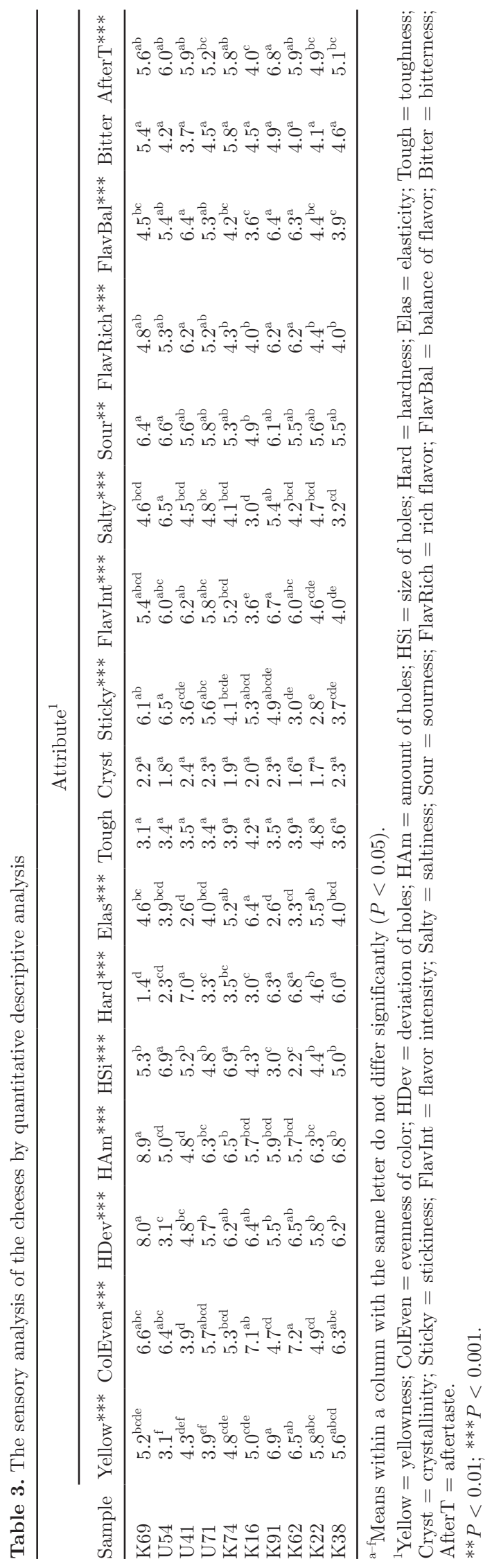


Table 4. The results of the consumer hedonic test

\begin{tabular}{lcccc}
\hline Sample & $\begin{array}{c}\text { Overall } \\
\text { liking }\end{array}$ & $\begin{array}{c}\text { Pleasantness } \\
\text { of flavor }\end{array}$ & $\begin{array}{c}\text { Pleasantness } \\
\text { of mouth feel }\end{array}$ & $\begin{array}{c}\text { Pleasantness } \\
\text { of appearance }\end{array}$ \\
\hline K69 & $6.69^{\mathrm{a}}$ & $6.56^{\mathrm{a}}$ & $6.57^{\mathrm{a}}$ & $6.75^{\mathrm{ab}}$ \\
$\mathrm{U} 54$ & $6.61^{\mathrm{a}}$ & $6.54^{\mathrm{a}}$ & $6.50^{\mathrm{a}}$ & $6.60^{\mathrm{abc}}$ \\
$\mathrm{U} 41$ & $6.56^{\mathrm{ab}}$ & $6.42^{\mathrm{a}}$ & $6.37^{\mathrm{ab}}$ & $6.68^{\mathrm{abc}}$ \\
$\mathrm{U} 71$ & $6.51^{\mathrm{ab}}$ & $6.26^{\mathrm{ab}}$ & $6.33^{\mathrm{ab}}$ & $6.90^{\mathrm{a}}$ \\
$\mathrm{K} 74$ & $6.48^{\mathrm{ab}}$ & $6.41^{\mathrm{ab}}$ & $6.31^{\mathrm{ab}}$ & $6.95^{\mathrm{a}}$ \\
$\mathrm{K} 16$ & $6.26^{\mathrm{ab}}$ & $6.21^{\mathrm{ab}}$ & $6.25^{\mathrm{ab}}$ & $6.68^{\mathrm{abc}}$ \\
$\mathrm{K} 91$ & $6.22^{\mathrm{ab}}$ & $6.07^{\mathrm{ab}}$ & $6.22^{\mathrm{ab}}$ & $6.24^{\mathrm{ad}}$ \\
$\mathrm{K} 62$ & $6.21^{\mathrm{ab}}$ & $6.16^{\mathrm{ab}}$ & $6.14^{\mathrm{abc}}$ & $6.67^{\mathrm{abc}}$ \\
K22 & $6.04^{\mathrm{bc}}$ & $5.88^{\mathrm{bc}}$ & $5.88^{\mathrm{bc}}$ & $6.31^{\mathrm{bcd}}$ \\
$\mathrm{K} 38$ & $5.67^{\mathrm{c}}$ & $5.53^{\mathrm{c}}$ & $5.61^{\mathrm{c}}$ & \\
\hline
\end{tabular}

${ }^{\mathrm{a}-\mathrm{d}}$ Means in a column marked with same letter do not differ significantly $(P<0.05)$.

5.266, $P<0.000$; pleasantness of flavor: $F=7.031, P$ $<0.000$; overall liking: $F=7.137, P<0.000)$. Eight out of 10 samples comprised group A in Tukey's test. The relatively high liking scores may be explained by the consumers' positive attitude. In addition, Tuorila et al. (1994) suggested that subjects who deliberately use reduced-fat products have positive expectations about all fat-free products. Furthermore, Solheim and Lawless (1996) have found that subjects with a positive attitude toward low-fat food rated reduced-fat Cheddar higher than its regular-fat counterpart. This fact was independent of the awareness of the fat content. In this study, no direct measurement of attitude was assessed. However, because food choice is a free choice, we assumed that consumers of reduced-fat cheeses purchased and ate the cheeses voluntarily.

The narrow range of liking was not unexpected. Hersleth et al. (2005) did not find any significant differences for liking of Norvegia cheeses, and in another study (Drake et al., 2008), overall liking of mild Cheddar varied from 5.3 to 6.6 on a 9-point hedonic scale. Consumers can be fickle in their preferences, thus mean values of liking scores can be nondiscriminating. Furthermore, Lawlor and Delahunty (2000) have shown that some consumer segments might be missed when only mean values of liking are taken into account.

In this study, one consumer was excluded from the preference mapping because of invariable scoring (the individual always chose the same value for liking). It is possible that more consumers were incapable of evaluating the samples, either because they could not sense any differences or were unable to use the scale. For instance, Lawlor and Delahunty (2000) excluded $18 \%$ of consumers, and Childs and Drake (2009) omitted 12\% in a Cheddar study and 14\% in a Mozzarella study. Liggett et al. (2008) used cluster analysis for the separation of nondistinguishers (40\% of respondents). However, in this study, no further selection of consumers was implemented. The preference mapping shows (Figure
1) consumers evenly spread throughout the map, hence selection of consumers was considered unnecessary.

\section{Chemical Analysis}

The fat content of the cheeses varied from 15.1 to $20.4 \%$, and the salt content varied from 0.7 to $2.3 \%$ (Table 5). The DM content is shown in Table 5 as another way to characterize the samples. The FAA levels varied in the same general range as that reported earlier (i.e., from 80 to $225 \mathrm{mmol} / \mathrm{kg}$; Table 5; Ritvanen et al., 2005). Madsen and Ardö (2001) reported total amounts of FAA ranging from 74 to $85 \mathrm{mmol} / \mathrm{kg}$ for 3 Danbo cheese with varying fat content and 7 -wk ripening time. The actual ripening times for the cheeses in this study are unknown; however, in general, Havarti-type cheeses are ripened for less than 6 mo.

Cheese is a noticeable source of salt in the diet (SaintEve et al., 2009). In an earlier study, the highest salt content in Havarti-type cheeses was $1.6 \%$ (Ritvanen et al., 2005), which indicates a possible tendency to increase the salt content in Havarti-type cheeses. The limit for heavy salting in cheeses has been set to $1.3 \%$ by weight in Finland. In light of the current legislation, 6 out of 10 samples examined were considered to be "heavy salted." The salt contents were slightly lower than the salt contents of commercial Cheddar cheese, which ranged from 1.3 to $3.3 \%$ (wt/wt), in one study (Kilcawley et al., 2007). In that study, the 2 reduced-fat Cheddar cheeses had $1.4 \%$ salt.

\section{Correlations to Chemical Analysis}

Neither "rich flavor" nor "balance of flavors" correlated with the fat content, as one might have predicted. This is in accordance with the findings of Saint-Eve et al. (2009), who found that butter perception was independent of fat content. Fenelon et al. (2000a) stated that full-fat Cheddar was rated as creamier and more buttery 

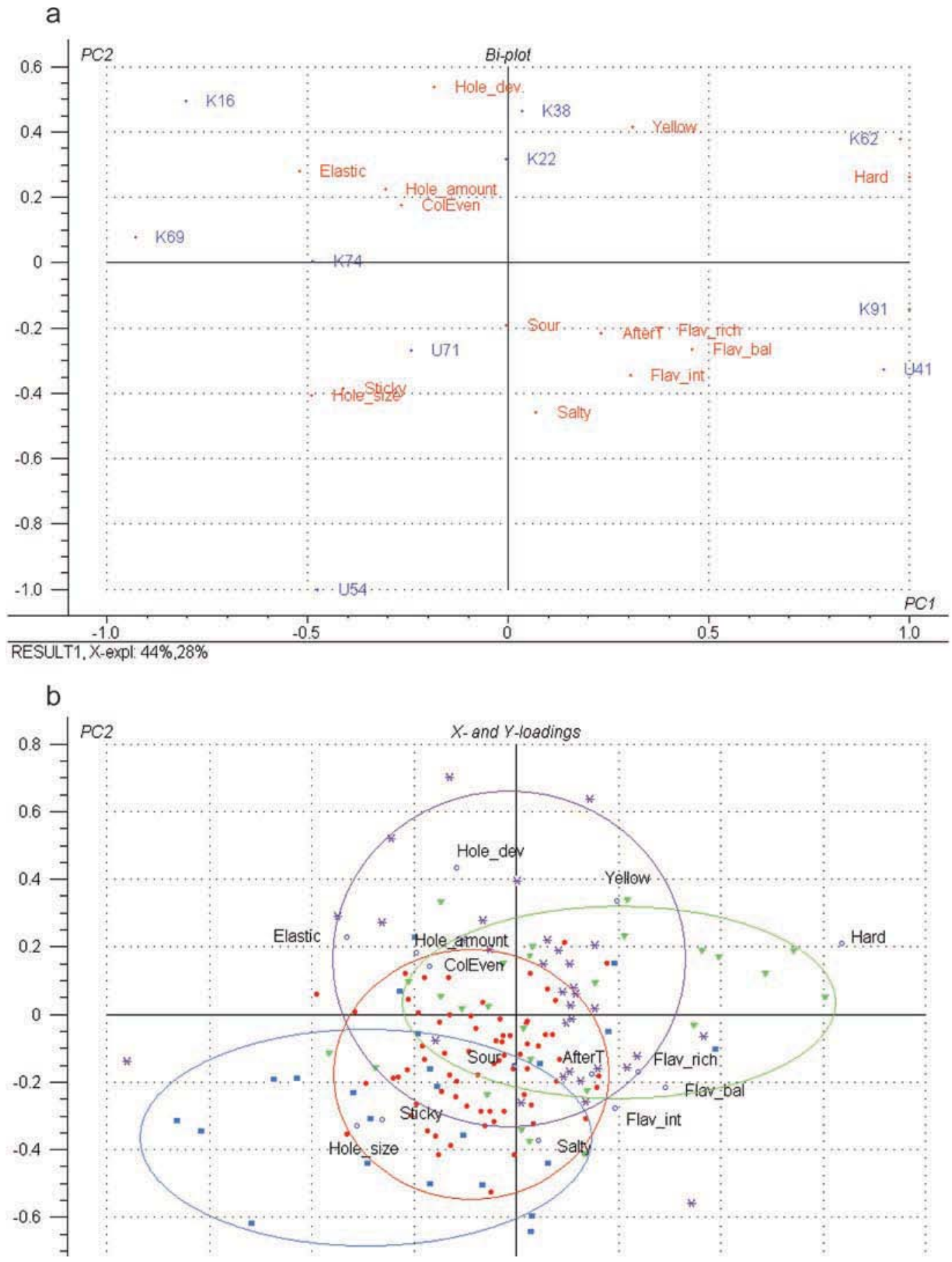

Figure 1. a) Principal component analysis (scores and loadings) of the samples and the quantitative descriptive analysis (QDA); b) principal component regression loadings of the QDA (x-variable) and the consumer hedonic tests (y-variable); preference mapping. The consumer subgroups are indicated by symbols (dot, star, triangle, and square); Yellow = yellowness; ColEven $=$ evenness of color; Hole_dev $=$ deviation of holes; Hole_amount = amount of holes; Hole_size = size of holes; Hard = hardness; Elastic = elasticity; Sticky = stickiness; Flav_int = flavor intensity; Salty $=$ saltiness; Sour $=$ sourness; Flav_rich $=$ rich flavor; Flav_bal $=$ balance of flavor; AfterT $=$ aftertaste. Color version available in the online PDF.

than reduced-fat cheeses. Furthermore, Kilcawley et al. (2007) stated that full-fat Cheddar was rated as more "balanced." In our study, all samples were reduced-fat cheeses and therefore similar connections between rich flavor and fat content could not be made. When fat content is constant, the differences in flavors associated with fat might originate from age. Caspia et al. (2006) found that a 9-mo-ripened cheese had a more cooked, 
Table 5. The chemical composition of the cheeses (mean values) ${ }^{1}$

\begin{tabular}{lcccc}
\hline Sample & Fat, $\%$ & DM, \% & Salt, \% & $\begin{array}{c}\text { Free AA, } \\
\text { mmol/kg }\end{array}$ \\
\hline K69 & 15.1 & 56.1 & 1.9 & 120 \\
U54 & 15.9 & 50.2 & 2.3 & 121 \\
U41 & 18.5 & 56.4 & 1.5 & 213 \\
U71 & 16.0 & 52.4 & 1.4 & 163 \\
K74 & 16.2 & 51.6 & 1.0 & 112 \\
K16 & 19.3 & 54.0 & 1.5 & 112 \\
K91 & 18.2 & 49.8 & 1.4 & 225 \\
K62 & 19.0 & 56.0 & 1.3 & 212 \\
K22 & 18.1 & 54.3 & 0.7 & 80 \\
K38 & 20.4 & 56.1 & 1.2 & 108 \\
\hline
\end{tabular}

${ }^{1}$ Fat and salt are expressed as a percentage of wet basis.

buttery, and creamy taste than the 7- or 12-mo-ripened cheeses. Furthermore, Fenelon et al. (2000a) proposed that "balanced" flavor reflects more subtle differences between cheeses in concentrations and types of volatile compounds developing during ripening.

Fat content did not correlate with the FAA levels, which is in contrast with the report of Kebary et al. (1999), in which a decrease in fat content caused a decrease in total FAA content. The lower moisture and higher salt contents of low-fat cheeses were postulated to suppress the growth of proteolytic bacteria. Fenelon et al. (2000b) also claimed that an increase in fat content would increase primary proteolysis in Cheddar. Nonetheless, the cheeses in our study were produced in different dairies and many other factors - for example, different manufacturing conditions - had a greater influence on FAA formation than did fat content (Madsen and Ardö, 2001).

Salt content may have a significant influence on saltiness, sourness, and yellow color (Wendin et al., 2000), but no such correlations were found. Salty flavor was independent of salt content $(P>0.05)$. The salty flavor was perhaps masked by other sensory attributes. Salt can also decrease bitterness (Mistry and Kasperson, 1998), but in this study, salt content did not affect bitterness.

The FAA levels were positively correlated with flavor intensity [Spearman correlation coefficient $\left(\mathbf{r}_{\mathrm{s}}\right)=0.915$; $P<0.05$ ], flavor richness $\left(\mathrm{r}_{\mathrm{s}}=0.892 ; P<0.05\right)$, balance of flavors $\left(\mathrm{r}_{\mathrm{s}}=0.890 ; P<0.05\right)$, and aftertaste $\left(\mathrm{r}_{\mathrm{s}}\right.$ $=0.787 ; P<0.05)$. It can be concluded that FAA formation is an important factor for the flavor of reducedfat Havarti-type cheeses. Pripp et al. (2006) found a similar correlation between FAA content and flavor intensity for Präst cheese. This also is in accordance with Fenelon et al. (2000a), who stated that total FAA content was independent of the fat content, but that FAA was a factor in discriminating between mild and mature Cheddar. Kilcawley et al. (2007) also reported that fat content had no influence on proteolysis.

\section{Correlations to Consumer Test}

The attributes correlating to overall liking are presented in Table 6. In this study of Finnish consumers of reduced-fat cheese, fat content correlated negatively to overall liking $(P<0.05$, Table 6$)$, even though fat content varied only slightly.

Salt content correlated positively to overall liking $(P$ $<0.01$, Table 6$)$, pleasantness of mouth feel $(P<0.05$, data not shown), and pleasantness of flavor $(P<0.05$, data not shown). Furthermore, the 2 most preferred cheeses were the most salted ones. Saint-Eve et al. (2009) found that a reduced-fat cheese with higher salt content was perceived as being more intense in overall aroma. This might also be the explanation here, although "flavor intensity" did not correlate directly to overall liking. Moreover, it is known that salt influences texture, and Saint-Eve et al. (2009) proposed that salt has a greater effect on products with a reduced fat content.

Eating highly salted cheeses may affect overall salt intake, which in turn is connected to the risk of hypertension. In this study, a preference for highly salted reduced-fat cheeses was observed. From a health standpoint, this is unfortunate because reduced-fat dairy products are recommended as a part of a healthy diet. It is evident that there is a need to devise a tasty lowfat cheese with only moderate salt content.

Pleasantness of mouth feel and flavor were clearly correlated with overall liking $(P<0.01)$; however, the pleasantness of appearance did not correlate to overall liking. It seems that consumers prioritize mouth feel and flavor over appearance. Similarly Young et al. (2004) found strong relationships between "overall acceptance" and "overall flavor liking," as well as "overall texture liking" of Cheddar. The overall liking correlated positively to the size of holes and stickiness, and negatively to yellow color and toughness $(P<0.05$, Table

Table 6. The consumer preferences, the quantitative descriptive analysis (QDA) attributes by experts, and the chemical attributes correlated to overall liking

\begin{tabular}{lc}
\hline Attribute & $\mathrm{r}_{\mathrm{S}}{ }^{1}$ \\
\hline Consumer preference attributes & \\
Pleasantness of flavor & $0.976^{* *}$ \\
Pleasantness of mouth feel & $1.000^{* *}$ \\
QDA attributes & \\
Yellowness & $-0.685^{*}$ \\
Hole size & $0.620^{*}$ \\
Toughness & $-0.734^{*}$ \\
Stickiness & $0.709^{*}$ \\
Chemical attributes & \\
Fat content & $-0.733^{*}$ \\
Salt content & $0.787^{* *}$ \\
\hline
\end{tabular}

${ }^{1}$ Spearman correlation coefficient.

${ }^{*} P<0.05$; ** $P<0.01$. 
6). However, in this study, differences between cheeses in toughness were statistically nonsignificant.

The pleasantness of appearance correlated positively to the size of holes and negatively to yellow color $(P$ $<0.05$, data not shown). A yellow color is usually associated with the fat content of cheese (Wendin et al., 2000). In this study of Finnish consumers of reducedfat cheeses, an attribute connected to the fattiness (i.e., yellowness) was not preferred.

Bitterness had a nonsignificant influence on the hedonic scores (data not shown). It can be concluded that although some bitterness might have been detected, this was not displeasing to the Finnish consumer.

\section{Preference Mapping}

Preference mapping was used to clarify the relationships between sensory characteristics and consumer preference (McEwan, 1996). One consumer was omitted because she rated all cheeses identically. In addition, the QDA variables with statistically nonsignificant differences between samples (crystallinity, bitterness, and toughness) were omitted. Two principal components (PC1 and PC2) explained $72 \%$ of the variation in the data. The results of principal component analysis and principal component regression are summarized in Figures $1 \mathrm{a}$ and $1 \mathrm{~b}$.

Cheeses K38 and K22 are adjacent in Figure 1a; they were the least-liked cheeses (group C in Tukey's test; Table 4). These particular cheeses were yellow and bland (i.e., no sense of saltiness or sourness), their flavor intensity was low, and they had many evenly distributed holes.

Cheeses U54 and K69 were 2 of the best-liked cheeses, yet they are far from each other in Figure 1. Both cheeses were sticky and soft, but differences in their sensory profile were observed. The most remarkable differences between these 2 cheeses related to yellowness and holes (amount and deviation of holes). These cheeses had the highest salt content (Table 5). However, sample U54 tasted saltier than K69. Figure 1 reveals that cheeses K62, K91, and U41 resemble each other more. This was a group of favored cheeses that were hard, nonelastic, and slightly yellow, with a moderately rich, balanced, and intense flavor. It can be concluded that although Finnish consumers may like different types of cheeses, they display a consensus in their dislikes.

The consumers are presented in Figure 1b. Four subgroups of consumers were created by cluster analysis according to their likings. This gives more information on differences between consumers. Subgroup $1(\mathrm{n}=67$; dot) consists of consumers who prefer sour and sticky cheese. The consumers in subgroup $2(\mathrm{n}=34$; star $)$ prefer cheeses with an intense flavor and many holes. This group is well dispersed on the map comprising consumers with the most varying preferences. The consumers in subgroup $3(\mathrm{n}=28$; triangle) like a hard, yellow cheese. Subgroup $4(\mathrm{n}=23$; square) consists of consumers who prefer sticky cheeses with large holes. It must be stated that the groups overlap to some degree. Subgroups 3 and 4 are the furthest away from each other. Consequently, on the one side of the preference map are sticky, soft, and pale cheeses and on the other side, hard and yellow cheeses.

It is evident that more information on consumer preferences could be obtained from preference mapping than from correlations with the consumer test alone. Young et al. (2004) have created a similar preference map for Cheddar. They distinguished 6 distinct consumer segments. In addition, Lawlor and Delahunty (2000) applied preference mapping and identified consumer segments for 10 specialty cheeses. Preference mapping in the present study highlights distinct consumer segments for reduced-fat Havarti-type cheeses with varying texture; moreover, a lack of flavor was considered to be unappealing to most Finnish consumers.

\section{CONCLUSIONS}

Finnish consumers preferred reduced-fat Havarti-type cheeses with a pale appearance, sticky consistency, and rich flavor. Nevertheless, consumers could be grouped according to their preferences mainly on yellowness and consistency. The least-preferred cheeses were those with the lowest flavor intensities. Salt content correlated with overall liking. It can be concluded that the reduced-fat Havarti cheeses on the market are well liked. However, cheeses with an intense flavor but with less salt are needed to meet the need for a tasty and healthy cheese.

\section{ACKNOWLEDGMENTS}

Financial support was received from the Ministry of Agriculture and Forestry and the Finnish dairy industry. The partners of this joint study were the National Veterinary and Food Research Institute (now Finnish Food Safety Authority Evira, Helsinki, Finland), MTT Agrifood Research Finland (Jokioinen), the National Consumer Research Centre Finland (Helsinki, Finland), Finnish Food and Drink Industries' Federation/Dairy Association (Helsinki, Finland), Valio Ltd. (Helsinki, Finland), Arla Ingman Ltd. (Söderkulla, Finland), and Milka co-operative dairy (Kaitsor, Finland). 


\section{REFERENCES}

Anon. 2007. Elintarvikelainsäädäntö. Mäkinen, ed. Edita Publishing Ltd., Helsinki, Finland.

Astrup, A., G. K. Grunwald, E. L. Melanson, W. H. M. Saris, and J. O. Hill. 2000. The role of low-fat diets in body weight control: A meta-analysis of ad libitum dietary intervention studies. Int. J. Obes. Relat. Metab. Disord. 24:1545-1552.

Banks, J. M. 2004. The technology of low-fat cheese manufacture. Int. J. Dairy Technol. 57:199-207.

Caspia, E. L., P. C. Coggins, M. W. Schilling, Y. Yoon, and C. H. White. 2006. The relationship between consumer acceptability and descriptive sensory attributes in Cheddar cheese. J. Sens. Stud. 21:112-127.

Childs, J. L., and M. Drake. 2009. Consumer perception of fat reduction in cheese. J. Sens. Stud. 24:902-921.

Davis, J. G. 1976. Havarti. Pages 782-783 in Cheese. Manufacturing Methods. Vol. 3. Churchill Livingstone, Edinburgh, UK.

Drake, S. L., P. D. Gerard, and M. A. Drake. 2008. Consumer preferences for mild Cheddar cheese flavors. J. Food Sci. 73:S449-455.

Fenelon, M. A., and T. P. Guinee. 2000. Primary proteolysis and textural changes during ripening in Cheddar cheeses manufactured to different fat contents. Int. Dairy J. 10:151-158.

Fenelon, M. A., T. P. Guinee, C. Delahunty, J. Murray, and F. Crowe. 2000a. Composition and sensory attributes of retail Cheddar cheese with different fat contents. J. Food Compos. Anal. 13:13-26.

Fenelon, M. A., P. O'Connor, and T. P. Guinee. 2000b. The effect of fat content on the microbiology and proteolysis in Cheddar cheese during ripening. J. Dairy Sci. 83:2173-2183.

Gwartney, E. A., E. A. Foegeding, and D. K. Larick. 2002. The texture of commercial full-fat and reduced-fat cheese. J. Food Sci. $67: 812-816$.

Helgesen, H., R. Solheim, and T. Næs. 1997. Consumer preference mapping of dry fermented lamb sausages. Food Qual. Prefer. 8:97-109.

Hersleth, M., M. A. Ilseng, M. Martens, and T. Næs. 2005. Perception of cheese: A comparison of quality scoring, descriptive analysis and consumer responses. J. Food Qual. 28:333-349.

IDF. 1982. Cheese and processed cheese-Determination of total solids content (reference method). IDF Standard 4a. Int. Dairy Fed., Brussels, Belgium.

IDF. 1986. Cheese and processed cheese-Determination of fat content-Gravimetric method (reference method). IDF Standard 5b. Int. Dairy Fed., Brussels, Belgium.

IDF. 1988. Cheese and cheese products-Determination of chloride content-Potentiometric titration method. IDF Standard 88a. Int. Dairy Fed., Brussels, Belgium.

Jack, F. R., J. R. Piggott, and A. Paterson. 1994. Use and appropriateness in cheese choice, and an evaluation of attributes influencing appropriateness. Food Qual. Prefer. 5:281-290.

Kähkönen, P., and H. Tuorila. 1999. Consumer responses to reduced and regular fat content in different products: Effects of gender, involvement and health concern. Food Qual. Prefer. 10:83-91.

Karppanen, H., and E. Mervaala. 2006. Sodium intake and hypertension. Prog. Cardiovasc. Dis. 49:59-75.

Kebary, K. M. K., A. H. El-Sonbaty, and R. M. Badawi. 1999. Effects of heating milk and accelerating ripening of low fat Ras cheese on biogenic amines and free amino acids development. Food Chem. 64:67-75

Kilcawley, K. N., P. B. O'Connell, D. K. Hickey, E. M. Sheehan, T. P. Beresford, and P. L. McSweeney. 2007. Influence of composition on the biochemical and sensory characteristics of commercial Cheddar cheese of variable quality and fat content. Int. J. Dairy Technol. 60:81-88.

Kris-Etherton, P. M., and S. Innis., American Dietetic Association, and Dietitians of Canada. 2007. Position of the American Dietetic
Association and Dietitians of Canada: Dietary fatty acids. J. Am. Diet. Assoc. 107:1599-1611.

Lawlor, J. B., and C. M. Delahunty. 2000. The sensory profile and consumer preference for ten speciality cheeses. Int. J. Dairy Technol. $53: 28-36$.

Levis, P. A., E. Chambers IV, and D. E. Johnson. 2000. Consumption and liking of a fat modified product during short trial periods. Nutr. Res. 20:791-804.

Liggett, R. E., M. A. Drake, and J. F. Delwiche. 2008. Impact of flavor attributes on consumer liking of Swiss cheese. J. Dairy Sci. 91:466-476.

Madsen, J. S., and Y. Ardö. 2001. Exploratory study of proteolysis, rheology and sensory properties of Danbo cheese with different fat contents. Int. Dairy J. 11:423-431.

McEwan, J. A. 1996. Preference mapping for product optimization. Pages 71-102 in Multivariate Analysis of Data in Sensory Science. T. Næs and E. Risvik, ed. Elsevier Science Ltd., New York, NY.

Meckling, K. A., C. O'Sullivan, and D. Saari. 2004. Comparison of a low-fat diet to a low-carbohydrate diet on weight loss, body composition, and risk factors for diabetes and cardiovascular disease in free-living, overweight men and women. J. Clin. Endocrinol. Metab. 89:2717-2723.

Mistry, V. V. 2001. Low fat cheese technology. Int. Dairy J. 11:413422

Mistry, V. V., and K. M. Kasperson. 1998. Influence of salt on the quality of reduced-fat Cheddar cheese. J. Dairy Sci. 81:1214-1221.

Moisio, T., and M. Heikonen. 1996. A simple method for the titration of multicomponent acid-base mixtures. Fresenius J. Anal. Chem. 354:271-277.

Peryam, D. R., and F. J. Pilgrim. 1957. Hedonic scale method of measuring food preferences. Food Technol. 11:9-14.

Pripp, A. H., S. Skeie, T. Isaksson, G. I. Borge, and T. Sørhaug. 2006. Multivariate modelling of relationships between proteolysis and sensory quality of Präst cheese. Int. Dairy J. 16:225-235.

Ritvanen, T., S. Lampolahti, L. Lilleberg, T. Tupasela, M. Isoniemi, U. Appelbye, T. Lyytikäinen, S. Eerola, and E. Uusi-Rauva. 2005. Sensory evaluation, chemical composition and consumer acceptance of full fat and reduced-fat cheeses in the Finnish market. Food Qual. Prefer. 16:479-492.

Saint-Eve, A., C. Lauverjat, C. Magnan, I. Déléris, and I. Souchon. 2009. Reducing salt and fat content: impact of composition, texture and cognitive interactions on the perception of flavored model cheeses. Food Chem. 116:167-175.

Scholz-Ahrens, K. E., and J. Schrezenmeir. 2006. Milk minerals and the metabolic syndrome. Int. Dairy J. 16:1399-1407.

Solheim, R., and H. T. Lawless. 1996. Consumer purchase probability affected by attitude towards low-fat foods, liking, private body consciousness and information on fat and price. Food Qual. Prefer. $7: 137-143$.

Stone, H., and J. L. Sidel. 1993. Sensory Evaluation Practices. Academic Press, San Diego, CA.

Tuorila, H., A. V. Cardello, and L. L. Lesher. 1994. Antecedents and consequences of expectations related to fat-free and regular-fat foods. Appetite 23:247-263.

Wendin, K., M. Langton, L. Caous, and G. Hall. 2000. Dynamic analyses of sensory and microstructural properties of cream cheese. Food Chem. 71:363-378.

Yackinous, C., C. Wee, and J.-X. Guinard. 1999. Internal preference mapping of hedonic ratings for Ranch salad dressings varying in fat and garlic flavor. Food Qual. Prefer. 10:401-409.

Young, N. D., M. Drake, K. Lopetcharat, and M. R. McDaniel. 2004. Preference mapping of Cheddar cheese with varying maturity levels. J. Dairy Sci. 87:11-19. 